\title{
EL PROCESO DE INDEPENDENCIA DE CATALUÑA: SU VISIÓN DESDE LA COMUNIDAD VALENCIANA
}

\author{
M. ${ }^{a}$ JOSEFA RIDAURA MARTÍNEZ \\ Catedrática $(A)$ de Derecho Constitucional \\ Universitat de Valencia
}

SUMARIO

I. Introducción. II. La Comunidad Valenciana en la Hoja de Ruta de la Independencia. III. La reivindicación de la singularidad propia de la Comunidad Valenciana como una constante en los procesos constituyente y estatuyente. IV. La respuesta institucional ante la Declaración de «desconexión de España». V. La identidad dual de la Comunidad Valenciana en el modelo de organización territorial.

\section{INTRODUCCIÓN}

Este trabajo afronta el problema de la independencia de Cataluña desde la concreta visión de la Comunidad Valenciana. Para su tratamiento debemos comenzar destacando que el fortalecimiento de las posiciones nacionalistas que se ha revelado en estos últimos años ${ }^{1}$, planteando la secesión y la desco-

1 Aunque no se trata de analizar en este trabajo ni los orígenes, ni el desarrollo del actual proceso soberanista, lo situaremos, por ponerle un inicio, en la reacción ante la Sentencia del Tribunal Constitucional relativa a la reforma del Estatuto de Autonomía de 2006, precedida de la manifestación de julio de 2010, cuyo lema Som una nació. Nosaltres decidim, que marcaba claramente el inicio de un proceso de rechazo a la Sentencia y de profundización, que tras sucesivos movimientos conducirá a la aprobación el 23 de enero de 2013 aprobó por el Parlamento de Cataluña, de la «Declaración de Soberanía y del derecho a decidir del Pueblo de Cataluña», manifestando que: «De acuerdo con la voluntad mayoritaria expresada democráticamente por parte del pueblo de Cataluña, el Parlamento de Cataluña acuerda hacer efectivo el ejercicio del derecho a decidir, para que los ciudadanos de Cataluña puedan decidir su futuro político colectivo...».

Pretensiones que se han ido fortaleciendo desde entonces y que han dado paso a la propuesta de Resolución 1/XI del Parlamento de Cataluña, de 9 de noviembre de 2015, sobre el inicio del proceso político en Cataluña como consecuencia de los resultados electorales del 27 de septiembre de 2015 presentada en el Parlamento catalán por los grupos parlamentarios Junts pel Sí y CUP, y aprobada sólo con el respaldo de dichos grupos. 
nexión catalana del Estado, afectan a la Comunidad Valenciana desde distintas perspectivas. En primer lugar, y con carácter general, la independencia de Cataluña transforma el modelo de organización territorial acuñado en la Constitución, pues la desmembración de un territorio integrante del Estado, soslayando todo procedimiento constitucional, afecta, tanto a la Comunidad Valenciana, como a cualquier otra Comunidad Autónoma que asiste al desvanecimiento del Estado y del propio modelo constitucional ${ }^{2}$. Modelo que, pese a la conveniencia de determinadas revisiones, ha permitido armonizar unidad con colaboración, solidaridad y lealtad como principios de ordenación del Estado Autonómico.

En segundo lugar, la Comunidad Valenciana afronta el problema de la independencia de Cataluña con un enfoque particular, en atención a su posición como Comunidad limítrofe a la Catalana, con la que antiguamente compartió la Corona de Aragón. Ello ha provocado, históricamente, una constante tensión ante el persistente conflicto por las pretensiones de su adhesión al Països Catalans. Esta permanente tensión entre la reivindicación valenciana de su propia autonomía, en el marco estatal, y la posible anexión a Cataluña se manifestó, ya, en los propios debates constituyentes; presidió los de elaboración del Estatuto de Autonomía, y, ahora, pervive ante las manifestaciones difundidas por representantes del proceso independentista catalán que incluyen a diversos territorios limítrofes, entre ellos a la Comunidad Valenciana, en esta desmembración del Estado, y su pretendida consolidación de unos Pä̈sos Catalans independientes del Estado.

Es cierto que dichas pretensiones, hoy en día, no tienen un respaldo, ni siquiera, significativo en la propia Comunidad Valenciana, ya que, como tendremos ocasión de ver, pese a la existencia de algunos grupos políticos que les darían soporte, la singularidad de la Comunidad Valenciana como una Comunidad propia en el marco estatal ha sido una constante revelada desde los inicios del proceso de descentralización y de la constitución de las propias Comunidades Autónomas y que, además, se ha ido fortaleciendo al compás de la propia consolidación de un modelo estatal descentralizado.

Así pues, en este trabajo analizaremos el conflicto planteado por la pretendida desconexión catalana resaltando, en primer lugar, las pretensiones independentistas de ampliar el Estado catalán con territorios de Comunidades limítrofes, bien mediante la futura anexión, bien mediante la anunciada federación. Estudiaremos, además, retrospectivamente, las razones que ya evidenciaron en el propio

2 Así el Tribunal Constitucional en la Sentencia de 2 de diciembre de 2015, respecto de dicha Resolución Declaración del Parlamento de Cataluña que inicia el llamado «proceso de desconexión» de españa ha declarado que «el planteamiento de concepciones que pretendan modificar el fundamento mismo del orden constitucional tiene cabida en nuestro ordenamiento siempre que se haga en el marco de los procedimientos de reforma previstos en la Constitución. Cuando, por el contrario, se pretenden alterar aquellos contenidos de manera unilateral y se ignoran de forma deliberada los procedimientos expresamente previstos a tal fin en la Constitución, se abandona la única senda que permite llegar a ese punto, la del Derecho. 
proceso de elaboración de la Constitución de 1978 la existencia de una aspiración clara de la Comunidad Valenciana por manifestar, mantener y fortalecer su singularidad como Comunidad Autónoma propia; que pervivió en el proceso estatuyente, y que se ha mantenido en las sucesivas reformas del Estatuto de Autonomía. Centrándonos, después, en la respuesta institucional de la Comunidad Valenciana ante la desconexión catalana, en cuanto que Comunidad Autónoma integrante del Estado, así como la posición manifestada por la sociedad valenciana en torno al modelo de organización territorial y la incidencia del nacionalismo independentista en esta Comunidad. Para realizar este trabajo nos hemos apoyado, principalmente, en las herramientas jurídicas que nos permiten abordar este problema de orden constitucional, en tanto que se centra en la estructura territorial del Estado; como en otras herramientas que nos permiten analizar los datos reales que revelan con claridad la tesis mantenida en este estudio: la clara identidad dual de la Comunidad Valenciana.

\section{LA COMUNIDAD VALENCIANA EN LA HOJA DE RUTA DE LA INDEPENDENCIA}

El proceso de independencia que ha conducido a la aprobación de la Declaración de Soberanía de 2013 se ha estado caracterizado, no sólo por la pretensión de conversión de Cataluña en Estado propio, independiente de España, sino que también ha extendido su anhelos a las Comunidades Autónomas que para los independentistas constituyen lo que debería ser el Estado catalán, esto es, los territorios integrantes de los denominados Países Catalanes. Ciertamente, son diversas las manifestaciones expresas que encontramos en aras de conseguir dicha pretensión. Sin ánimo de exhaustividad, sirven como ejemplo las siguientes, que ilustraran sobradamente esta afirmación ${ }^{3}$ :

La Hoja de Ruta de la Asamblea Nacional Catalana contemplaba en su última fase que las Cortes Valencianas sometieran a votación la posibilidad de establecer una federación entre Cataluña y la Comunidad Valenciana. Asimismo, el Proyecto de Declaración Fundacional de dicha Asamblea Nacional contiene en su punto octavo la siguiente declaración: 8. - «Mentre no es constitueixin al País Valencià, a les Illes Balears $i$ a la Catalunya Nord assemblees nacionals amb els mateixos objectius que els de l'ANC, aquesta acollirà al seu si tots els compatriotes d'aquells països que vulguin vincular-s'bi $i$ els donarà tot el suport possible amb aquella finalitat, tot respectant els diferents processos i ritmes de cada país. Un cop constituït en un altre país de nació ca-

3 El borrador de Constitución Catalana en su artículo 35.1 establece que «Cataluña limita al norte con Francia, al sur y al oeste con España. Se compromete a mantener los actuales limites territoriales, sin perjuicio de fomentar los especiales vínculos con las tierras de habla catalana bajo soberanía de otros Estados».

Redactada por un grupo de juristas liderado por el magistrado de la Audiencia de Barcelona Santiago Vidal. http://www.aelpa.org/actualidad/201502/BorradorConstitucioCatalana.pdf 
talana un moviment unitari consemblant a l'ANC, s'bi establiran formes de reconeixement recíproc dels membres respectius i de coordinació per a la solidaritat i l'ajut mutus»'.

Más explícitamente, Esquerra Republicana de Cataluña ${ }^{5}$, impulsora esencial del proceso soberanista de independencia, mantenía en su Programa para las pasadas elecciones europeas extender el proceso secesionista a la Comunidad Valenciana y a Baleares. Posición que sigue manteniendo en la actualidad al reafirmar su compromiso con la creación del Proyecte Polític per al Països Catalans ${ }^{6}$.

La rotundidad de sus objetivos se revela en el Programa Electoral de esta formación política en las Elecciones Generales de 2015, en el que se propone que para el nacimiento del nuevo Estado Catalán se profundice en los vínculos con el resto de los Països Catalans. En esta dirección postulan compartir un proyecto nacional común desde la cooperación y el reconocimiento mutuo de sujetos políticos, a partir del respeto a la voluntad soberana y el derecho a decidir de cada territorio». Considerando crucial la presencia de Islas Baleares, País Valencià y Catalunya del Nord en el proceso constituyente de la República de Catalunya ${ }^{7}$. Para ello proponen cooperar en la articulación de un proceso que pueda culminar en una República de estos territorios para que pueden reunificarse en los términos que cada parte acuerde. De ahí que, cuando se constituya el nuevo Estado catalán proponen que los habitantes del resto de los Països Catalans puedan añadir a su nacionalidad española, también, la catalana; facilitando, asimismo, entre otros, la presencia de dichos territorios en las Instituciones del nuevo Estado ${ }^{8}$.

4 Barcelona, Palau de Congressos, 30 d'abril de 2011. Puede consultarse en la Web de dicha Asamblea Nacional: https://assemblea.cat/. "Mientras no se constituyan en el País Valenciano, en las Islas Baleares y en la Cataluña Norte asambleas nacionales con los mismos objetivos que los del ANC, ésta acogerá como suyos a todos los compatriotas de aquellos países que quieran vincularse y les dará todo el apoyo posible con aquella finalidad, respetando los diferentes procesos y ritmos de cada país. Una vez constituido en otro país de la nación catalana un movimiento unitario equiparable a la ANC, se establecerán formas de reconocimiento recî roco de los miembros respectivos y de coordinación para la solidaridad y ayuda mutuas».

5 En la página 154 de su Programa electoral para las elecciones de 2012, expresamente recogía que «El sistema cultural públic ha de ser capaç de desplegar les nostres polítiques als Pä̈sos Catalans $i$, sempre que sigui possible, d'acord amb les entitats arrelades a la societat civil dels territoris d'Andorra, Balears, la Franja, Catalunya del Nord, l'Alguer, el País Valencià i, per suposat, del Principat. Aquest sistema cultural públic ha de treballar per defensar $i$ impulsar la tasca dels creadors $i$ de les industries culturals».

$6 \mathrm{http}: / /$ www.esquerra.cat/partit/projecte-politic/projecte-ppcc.

7 La página 15 del Programa está dedicada a este concreto objetivo. http://www.esquerra.cat/partit/ programes/e2015-programa.pdf

8 Proponen también como objetivos: «El establecimiento de un ministerio u organismo que se ocupe específicamente de las relaciones transfronterizas e impulsos políticos y convenios con instituciones, entidades o empresas para promover y desarrollar el patrimonio compartido con los Estados vecinos. - «La República catalana llevará a término acciones de promoción de la lengua en todos los territorios en que es propia». - «La simbología histórica y tradicional compartida por todos los territorios de los Países Catalanas no será de uso exclusivo de la nueva República. Tanto el nuevo Estado como sus medios y organismos públicos difundirán y divulgarán esta realidad común. Por eso será necesario impulsar la articulación de este espacio comunicativo catalán, formado por los medios de comunicación de Cataluña y los medios de comunicación del resto de los territorios históricos de los Países Catalanes». - «El impulso a la creación de alguna instancia donde puedan coincidir y estrechar vínculos los cargos electos de todos los Países Catalanes para tratar agendas de intereses comunes» - «El nuevo Estado pondrá a disposición de los creadores culturales y artísticos de los demás Países 
Por su parte la CUP reconoce claramente en su Diario de Campanya el inicio del proceso constituyente dirigido a «un largo camino hacia unos Països Catalans plenamente libres y solidarios» ${ }^{9}$.

Además, el fomento dels Països Catalans no sólo es una cuestión política, sino que viene respaldada también por una inversión económica desde Cataluña. Las cifras desvelan que una Comunidad como la Catalana, que es la segunda Comunidad con mayor déficit fiscal, pues tiene un saldo negativo de más de ocho mil millones de euros, sólo tomando como referencia el año los dos últimos años, en subvenciones al fomento y apoyo del Catalanismo en la Comunidad Valenciana ha superado con creces el millón de euros ${ }^{10}$.

Catalanes sus organismos de proyección exterior» - «la voluntad de incorporar, en el proceso de elaboración de la futura Constitución catalana, la definición y el marco completo de la nación, teniendo en cuenta aspectos como el reconocimiento de la condición nacional a los ciudadanos de los otros territorios que libremente lo reclamen o la inclusión de una cláusula democrática de eventual reunificación futura, como tenía la Constitución de la República Federal Alemana o la de Irlanda de 1937, aún respetando de forma escrupulosa el derecho democrático a decidir de los ciudadanos de cada territorio».

9 En el Documento «el motor es la gent. 27.s 2015. Diario de Campanya de la CUP Crida Constituent per al 27S, http://cup.cat/document/diari-de-campanya-de-la-cup-crida-constituent-al-27s.

O la aparición en la cuenta oficial de Twitter de la candidatura a las elecciones de noviembre de 2015 que lideraba Artur Mas de un mapa de la Gran Cataluña que incluía a Aragón, la Comunidad Valenciana y Baleares. Mapa que se retiró tras la denuncia y las criticas de colectivos no independentistas 11 de noviembre de 2015, día de la Diada, figurando entre los denunciantes el colectivo Dolça Catalunya, contrario al proyecto independentista.

10 Sin ánimo de exhaustividad, sólo a título de ejemplo, entre otras, vid. la RESOLUCIÓ PRE/2155/2015, de 14 de septiembre, de concesión de la Subvenciones concedidas mediante convenio al amparo de los artículos 90.3 y 94.5 del Texto refundido de la Ley de finanzas públicas de Catalunya, aprobado por Decreto Legislativo 3/2002, de 24 de diciembre:

Entitat: Acció cultural del País Valencià. Finalitat: Activitats culturals de l'entitat durant l'any 2015. Import: 280.000,00 euros. Aplicació pressupostària: PR0101D/482000100/1210. Diari Oficial de la Generalitat de Catalunya, n. ${ }^{\circ}$ 6968-2.10.2015

Que está considerada en la web de la Generalitat como una de las Entidades culturales emblemáticas de los Países Catalanes: «ACPV está vinculada a la editorial Tres i Quatre y al semanario de información general 'El Temps', y tiene la sede actual en el Octubre Centro de Cultura Contemporánea, inaugurado en el 2006 en los antiguos almacenes El Siglo de la capital valenciana. Tiene delegaciones por todo el País Valenciano y representaciones autónomas en la Franja de Ponent y la Cataluña del Norte (los llamados casales Jaume I)». www.gentcat.cat.

Y en Diari Ofucial de la Generalitat de Catalunya n. ${ }^{\circ}$ 6858, 24.4.2015 Vid. RESOLUCIÓ PRE/725/2015, de 13 de abril:

Entitat: Fundació Ausias March. Finalitat: finançament de cursos de llengua i cultura catalanes i la campanya «Criteris per una política lingüística al País Valencià», durant l’any 2014. Import: 30.000,00 euros. Aplicació pressupostària: PR0101 D/481.00.01.00

Entitat: Acció cultural del País Valencià. Finalitat: finançament de la quota del préstec hipotecari derivat de la compra i adequació de l'edifici «El Siglo», corresponent a l'any 2014. Import: 670.073,27 euros. Aplicació pressupostària: PR0101 D/782.00.01.00

- Entitat: Acció Cultural del País Valencià. Finalitat: activitats culturals de l'entitat durant l'any 2014. Import: 250.000,00 euros. Aplicació pressupostària: PR0101 D/482.00.01.00. - Entitat: Edicions del País Valencià, SA. Finalitat: mitjà informatiu digital www.eltemps.cat; Import: 3.674,46 euros. Aplicació pressupostària: PR1201 D/470.00.01.00. - Entitat: Mas Mut Produccions, SLU. Finalidad: medio informativo digital www.comarquesnord.cat. Importe: 7.337,62 euros. Aplicación presupuestaria: PR1201 D/470.00.01.00. - Entidad: Comunicacions dels Ports, SA. Finalidad: la emisora Nord Televisió. Importe: 34.155,57 euros.

UNED. Teoría y Realidad Constitucional, núm. 37, 2016, pp. 381-404 


\section{LA REIVINDICACIÓN DE LA SINGULARIDAD PROPIA DE LA COMUNIDAD VALENCIANA COMO UNA CONSTANTE EN LOS PROCESOS CONSTITUYENTE Y ESTATUYENTE}

La conformación de la Comunidad Valenciana como una Comunidad propia ha constituido una reivindicación que se reveló desde los orígenes del proceso constituyente, planteándose firmemente durante la elaboración de la Constitución de 1978, y reafirmándose durante el propio proceso de construcción autonómica y de aprobación de su Estatuto de Autonomía.

\section{El planteamiento de prohibición de federación entre Comunidades Autónomas como cautela}

\section{a) Su relevancia política}

El artículo 145.2 CE regula como instrumentos para articular las relaciones entre las Comunidades Autónomas por un lado, Convenios para la gestión y prestación de servicios propios de las mismas; por otro, pueden adoptar Acuerdos de cooperación, para los que se requiere la previa autorización de las Cortes Generales. Pero, lo relevante a efectos del presente trabajo no es el estudio de dichas figuras convencionales, sino el que esta regulación viene precedida de la prohibición de federación de Comunidades Autónomas (art. 145.1). Se trata, ésta, de una cláusula ad cautelam prevista en muchos de los ordenamientos de Estados compuestos, que también estaba contemplada en la Constitución española de 1931 cuyo artículo 13 rezaba «En ningún caso se admite la federación de regiones autónomas».

Ciertamente, este apartado acaparó una especial atención en los debates constituyentes; expresando, en principio, el temor de que dicha federación pudiera quebrar la unidad del Estado. En efecto, como resalta Ignacio González, durante el proceso constituyente se reveló como una de las mayores preocupaciones de los partidos la articulación de un modelo que no quebrara la unidad territorial; singularmente, la redacción del artículo 145 reveló dicha preocupación, respondiendo a la clara intención de no dejar puertas abiertas a posibles alianzas políticas entre territorios autónomos que pudieran poner en cuestión el principio de unidad nacional ${ }^{11}$.

Sin embargo, su inclusión no respondía, precisamente, a la voluntad de marcar frenos preventivos a la federalización del modelo de Estado; y ello por diversas razones: en primer lugar, porque, como acertadamente se ha señalado, no existe

11 GonZÁlez García, I.: «La prohibición constitucional de federación entre Comunidades Autónomas», Cuadernos de Alzate, n. ${ }^{\circ}$ 40/2009. 
un nexo de relación directa entre la forma de la organización territorial y esta prohibición; esto es, su inclusión no se entiende como un rechazo al modelo federal. En segundo lugar, porque tampoco parece verosímil este argumento, pues esta prohibición está, incluso, prevista en algunos modelos federales ${ }^{12}$; de modo que aplicar una técnica que caracteriza a algunos sistemas federales para prohibir la federalización tiene difícil justificación ${ }^{13}$; de ahí que este precepto fuera calificado de desafortunado ${ }^{14}$.

Aunque debemos subrayar que la razón que condujo a sus proponentes a la inclusión de esta cláusula en la Constitución del 78, no fue, en sí, el freno al federalismo como modelo de organización territorial, sino la respuesta a una problema concreto: el temor a la posible absorción de las tres provincias valencianas por Cataluña en la futura configuración del mapa autonómico. En definitiva, se introdujo, precisamente, no para poner freno al federalismo, sino para poner freno a un posible mapa autonómico que abarcara los denominados Pä̈sos Catalans, y no tanto por temor a crear una Gran Comunidad que pudiera imponerse al resto del Estado, sino para evitar la inclusión en ellos de los valencianos; precisamente esta es la razón de que su autoría sea valenciana.

Estamos ante problema que tiene larga trayectoria; así lo revelan los debates constituyentes, como podremos apreciar a continuación. En efecto, el Anteproyecto de Constitución (art. 130) no preveía dicha cláusula ${ }^{15}$; fue la Ponencia en el Congreso la que aceptó como única la Enmienda (n. ${ }^{\circ} 33$ ) presentada por Jarabo Paya (diputado valenciano de Alianza Popular), que incluía la cláusula «en ningún caso podrá constituirse la federación de regiones autónomas». La justificación de la enmienda era clara: "..es importante que expresamente se haga constar en

12 Esta prohibición aparece también en otros países de estructura federal o compleja: artículo 7 de la Constitución de Suiza; artículo 1, sección 10, apartados 1 y 3 de la Constitución de los Estados Unidos de América; artículo 117 de la Constitución de México de 1917; artículo 108 de la Constitución Argentina de 1853. En Alemania, esa prohibición se infiere de los principios fundamentales de la Constitución por vía interpretativa», vid un estudio más detallado en García Morales, M.J.: Convenios de colaboración en los sistemas federales europeos: Estudio comparativo de Alemania, Suiza, Austria y Bélgica, Madrid, Mac-Graw-Hill, 1998; asimismo, vid. Sinopsis del Artículo 145 CE realizada por Mariano Bacigalupo Sagesse, en Portal de la Constitución, Congreso de los Diputados (http://congreso.es).

13 Santolaya MachetTi, P.: Descentralización y cooperación, Madrid, Instituto de Estudios de Administración Local, 1984, pp. 381-384. Tajadura TejadA, J.. «el Derecho Constitucional Comparado nos muestra que la prohibición de federación no es un criterio válido para distinguir el Estado federal del que no lo es por la sencilla razón de que dicha prohibición existe, de una u otra forma, en todos los Estados federales», «Los convenios de cooperación entre Comunidades Autónomas: marco normativo y propuestas de reforma», REAF, n. ${ }^{\circ} 11$, octubre 2010 , p. 216.

14 García Roca, J.: «El principio de voluntariedad autonómica: teoría y realidad constitucionales», Revista de Derecho Político, n. ${ }^{\circ}$ 21/1988, p. 119. Considerando que teniendo una doble finalidad el precepto: establecer un límite garantizador de la forma unitaria del Estado y evitar la construcción de los llamados Països Catalans, a su juicio la cláusula sólo cumple la segunda de estas finalidades, cit. p. 120.

15 En efecto, el artículo 130 del Anteproyecto de Constitución, se refería sólo a que las Cortes Generales autorizaran mediante ley orgánica «cualquier acuerdo de cooperación entre Territorios Autónomos». Exigencia que se matizó en la Comisión de Asuntos Constitucionales y Libertades Públicas del Congreso al suprimirse dicha reserva de ley orgánica.

UNED. Teoría y Realidad Constitucional, núm. 37, 2016, pp. 381-404 
la Constitución esta probibición, tal y como figuraba exactamente en el artículo 13, en la Constitución de la República, con objeto de evitar la fusión, integración o absorción de unas regiones con otras, posibilidad ésta que despierta inevitables recelos y tensiones, cuando no violento rechazo por parte de muchas provincias españolas, y que, caso de que llegara a materializarse, se traduciría en el nacimiento de bloques que desequilibrarían grave, y puede que definitivamente, la necesaria igualdad de fuerzas de las distintas regiones españolas, y que además, de suponer la perdida de la propia personalidad e independencia constituiria una indudable peligro para la unidad nacional» ${ }^{16}$.

Pese a que siguió insistiéndose por parte de algunos parlamentarios en la formulación de esta cláusula como freno al federalismo ${ }^{17}$; sin embargo, el debate en el Pleno del Congreso viró entorno a la singularidad de la lengua valenciana y al problema de los Países Catalanes ${ }^{18}$. Pero, verdaderamente, la Enmienda n. ${ }^{\circ} 33$ no pretendía frenar sólo un tema de lengua; así lo confirmaban las palabras de Puyol Soler (Minoría Catalana), quien en su explicación de voto, apelaba a la idea de justicia para justificar «fórmulas más profundas y más estables de vinculación» en el marco de las grandes colectividades histórico-lingüístico-culturales de España (el bloque vasco, el bloque gallego, y el bloque catalán). Siendo consciente de que ello podría producir «una grave fractura en el cuerpo social de estas colectividades» ${ }^{19}$.

Estas manifestaciones revelaban la auténtica finalidad de la enmienda: frenar la inclusión de las regiones valencianas en el bloque catalán, y con ello, reafirmar la singularidad propia y la formación de una Comunidad propia; de las palabras de Jarabo Paya así se desprendía cuando afirmaba «..nos consideramos un pueblo distinto, independiente, con una personalidad y una identidad absolutamente diferenciadas» ${ }^{20}$.

16 Enmienda n. ${ }^{\circ} 33$, Trabajos Parlamentarios. Vol. I, p. 144. Dicha Enmienda se aprobó por mayoría de los Grupos de Unión de Centro Democrático y Alianza Popular, Trabajos Parlamentarios, vol. I, p. 581. Un estudio más detallado de la elaboración de este precepto lo desarrollan TAJADURA TEJADA, J.: «El articulo 145 de la Constitución española: los Convenios y acuerdos de Cooperación entre las CCAA», Revista jurídica de Navarra, n. ${ }^{\circ}$ 21, 1996, pp. 113-142. SÁnchez NAvarro, A.: «el Artículo 145, Convenios entre Comunidades Autónomas», en Alzaga Villaamil, O.: Comentarios a la Constitución española de 1978, Edersa, Madrid, 1999, Tomo XI, pp. 89 y ss.

17 En este sentido se manifestaba Letamendía Belzune, vid. Trabajos Parlamentarios, ob.it, , Tomo. II, pp. 1534-1535.

18 Las críticas a la deriva de esta discusión las plantean Santolaya Machetti, P.: Descentralización y cooperación, ob. cit., p. 389, así como Tajadura Tejada, J.. « El artículo 145 ...», ob. cit., p. 117.

19 Manifestando que no iban a plantear ninguna iniciativa en este sentido, sino que «iniciativa debía surgir del País Valenciano y de las Islas Baleares, no de nosotros. Sabemos, repito, que esto tendría defensores; también tendría acérrimos y agrios detractores y, en último término, se produciría una profunda, una grave fractura en el cuerpo social de estas colectividades», Trabajos Parlamentarios, ob. cit, pp. 2422-2423. Sotillo Marti (Grupo Socialista) resaltaba que con el voto de su Grupo a favor el precepto se quería resaltar que no había proyecto de federación con ninguna otra comunidad, , desvinculando el artículo 138 del Estado Federal, ya que el artículo 138 (entonces) no puede reconocer acuerdos o pactos de soberanía entre comunidades autónomas, «porque eso desequilibraría toda la sistemática de la Constitución», p. 2427.

20 Trabajos Parlamentarios, ob. cit, p. 2430. 
Un claro exponente de que éste era el tema clave que realmente se suscitaba en este debate fue el hecho de que al aprobarse el precepto por el Pleno un centenar de intelectuales de los Països Catalans dirigieron a los parlamentarios un texto en el que defendían los derechos nacionales de éstos, evidenciando con ello que dicho precepto iba a ser un obstáculo para su consecución ${ }^{21}$.

Las pretensiones de expansión catalanista se volvieron a plantear en el Senado, como lo revela la intervención del catalán Rosendo Audet al calificar este artículo de: «centralista, jacobino y vejatorio», porque impide las relaciones plenas entre Cataluña, el País Valenciano y las Islas Baleares, en aras de permitir una posible federación aunque fuera estrictamente cultural y lingüística ${ }^{22}$.

La respuesta la ofrecía Joaquín Farnós (UCD) reafirmando la línea mantenida en el Congreso, cuando afirmaba que el pueblo valenciano desea una estrecha colaboración con Cataluña, pero tiene su identidad propia «y que queremos ser dueños de nuestro destino dentro del conjunto de todos los pueblos que forman España» ${ }^{23}$.

\section{b) Su significado jurídico}

Este debate pone de manifiesto que la relevancia del artículo 145.1 es política y no jurídica. En efecto, la prohibición de federación entre Comunidades Autónomas, como se ha convenido mayoritariamente, no implica en si un límite a la federalización del modelo de organización territorial, no constituyendo dicha prohibición un elemento definidor del modelo de Estado ${ }^{24}$; pues dichos elementos configuradores los encontramos en otros preceptos, en concreto en el artículo 2 que diseña una estructura descentralizada que pivota sobre la unidad, la autonomía y la solidaridad, desarrollados en el Título VIII. El verdadero significado jurídico de este precepto descarta, como apuntó Rodríguez Zapata, «toda alteración que altere el equilibrio político y territorial existente entre las Comunidades Autónomas y con el Estado; la formación de bloques políticos que puedan enfrentar entre sí a distintas Comunidades; las ligas o alianzas en-

21 Vid. Con más detalle Garrido Mayol, V.: «Consideraciones jurídico-políticas del proceso autonómico valenciano», en Ferrando BADía, J. (coord.) Estudios sobre el Estatuto Valenciano, tomo I, Consell Valencià de Cultura, Valencia, 1993, p. 172.

22 Así manifestaba que ... «Conjuntamente componemos unas realidades históricas, con una unidad de lengua y cultura que, lógicamente, deberían llevarnos a una libre federación de las distintas entidades autónomas...» Diario de Sesiones del Senado, n. ${ }^{\circ}$ 65, de 3 de octubre de 1978, pp. 3237-3238.

23 Ibidem, p. 3243.

24 Santolaya Machetti, P.: Descentralización y cooperación ..., ob. cit. pp. 381 y ss. Tajadura TejaDA, J.: El artículo 145, ob. cit. pp. 119 y ss; SÁNChez NAVArro, A.: «el Artículo 145..», ob. cit. pp. 89 y ss. En el mismo sentido, apunta IGNACIO GoNZÁLEZ en los debates constituyentes se vinculó erróneamente, tanto en los debates constituyentes del 31 como del 78 con la forma territorial del Estado, «identificando con notable impericia la idea de la federación entre regiones con una categoría jurídicamente diferenciable: la alteración de los límites territoriales de un mapa autonómico no definido constitucionalmente», Cuadernos de Alzate, ob. cit, p. 94. 
tre Comunidades incompatibles con la solidaridad o lealtad interregional o con el interés nacional» ${ }^{25}$.

Esta posible federación entre Comunidades Autónomas no tendría encaje constitucional ni en nuestro modelo, ni tampoco en un modelo federal; ya hemos apuntado con anterioridad que muchos Estados, pese a ser federales, contemplan tal prohibición. De forma que aunque desapareciera el 145.1 tampoco podría lograrse la federación entre Comunidades Autónomas — como subrayó desde los inicios Santolaya Machetti- tanto en virtud del principio de indisponibilidad de las competencias, como por la limitación de alcanzar acuerdos entre ellas sólo en las materias de su respectiva competencia $(145.2)^{26}$. Sin embargo, la cuestión de fondo que se planteaba al introducir el apartado primero del artículo 145 jurídicamente tiene otras connotaciones, ya que realmente lo que se quería evitar era la posible fusión de Comunidades Autónomas, o la absorción de una Comunidad por otra. Pero, ambos temas nos conducen a cuestiones de articulación jurídica distintas.

En primer lugar, en relación con la posible fusión de Comunidades Autónomas, es cierto que el texto constitucional no ofrece un mapa territorial, por tanto, no delimita el territorio de cada Comunidad Autónoma. De modo que la cuestión que se nos plantea en este caso es determinar si constitucionalmente podría articularse alguna vía para la modificación de los límites territoriales de una Comunidad Autónoma para fusionarse con otra u otras ${ }^{27}$.

En todo caso, no parece que el artículo 145.1 sea la vía idónea para permitir que determinadas Comunidades Autónomas blinden sus límites territoriales. Afirmaba, en este sentido Tajadura que la prohibición de federación no «constituye base suficiente para impedir la modificación de un mapa por lo demás inexistente» ${ }^{28}$. Tengamos en cuenta que la configuración de dicho mapa territorial tiene como eje vertebrador el principio dispositivo, ya que el territorio de cada Comunidad Autónoma se configura de acuerdo con el artículo 143 de la Constitución por la voluntad manifestada por las provincias limítrofes con características históricas, culturales y económicas comunes, los territorios insulares y las provincias con entidad regional histórica que manifiesten la voluntad de acceder a su autogobierno y constituirse en Comunidades Autónomas. Esta iniciativa del proceso autonómico

25 Rodríguez-Zapata Pérez, A.: «Artículo 145. Convenios entre Comunidades Autónomas», en Comentarios a las Leyes Políticas. La Constitución española de 1978, Alzaga Villaamil. O (dir.), Tomo XI, Edersa, Madrid, 1988, p. 68.

26 Ob. cit. p. 383.

27 Además, del supuesto previsto en la Disposición Transitoria 4. a de la Constitución que prevé expresamente la posible incorporación de Navarra, al Consejo General Vasco o al Régimen Autonómico Vasco.

28 Ob. cit., pp. 216-217. Pronunciándose en contra de la prohibición de tales fusiones, y entendiendo que el constituyente no pudo o no quiso establecer tal rigidez: RoDríGUEZ ZAPATA y PÉrEZ, J.: «Comentario al artículo 145», en Alzaga Villaamil, O. (dr.): Comentarios a las Leyes Políticas, Tomo XI, Edersa, Madrid, 1988 , p. 68. 
corresponde a todas las Diputaciones interesadas o al órgano interinsular correspondiente y a las dos terceras partes de los municipios cuya población represente, al menos, la mayoría del censo electoral de cada provincia o isla (143.2).

De modo que, es cierto que el texto constitucional no contiene un mapa autonómico, sino los sujetos que pueden promover la constitución de una Comunidad Autónoma. Pero conviene tener en cuenta que cuando arranca el proceso autonómico, en concreto el valenciano, aún no había entrado en vigor la Constitución. De hecho, ya el 30 de marzo de 1976, los Presidentes de las Diputaciones de Alicante, Castellón y Valencia acuerdan solicitar al Gobierno de la Nación que dictara las disposiciones oportunas para que, «respetando las características de cada provincia», se lograra, «dentro del marco constitucional del Estado, una autonomía», que reconociera «la personalidad del Reino» y permitiera su desarrollo en todos los aspectos. De este modo estaba conformándose la voluntad de establecer los límites territoriales de la que sería después la Comunidad Autónoma. Sin embargo, como advierte Diez-Revorio, el hecho de que los entes preautonómicos estuvieran aprobados mediante decretos-leyes al aprobarse la Constitución ${ }^{29}$ ello no implicaba ni que el mismo fuese a convertirse en Comunidad Autónoma, ni que, en caso afirmativo, su configuración fuese a permanecer inalterada. Aunque, en la mayoría de los casos, se siguieron las pautas de la distribución territorial preautonómica con escasas variaciones, cerrándose el mapa con los Acuerdos Autonómicos de $1981^{30}$.

No obstante, ello no descarta que una vez constituida la Comunidad Autónoma pudiera plantearse la fusión entre ellas. Ciertamente, la Constitución española de 1978 no contempla expresamente esta posibilidad ${ }^{31}$; a diferencia de otros textos constitucionales que si que la recogen; es el caso de Ley Fundamental Alemana cuyo artículo 29 está dedicado a la Reorganización del territorio federal ${ }^{32}$, exigien-

29 Díez-Revorio, J.: «Proceso constituyente y proceso descentralizador: ;de donde venimos y adonde vamos?, en El Futuro Territorial del Estado Español, Oliver Araujo, J. (dr.), Tirant lo Blanch, Valencia, 2014. Ilustrando el autor esta afirmación con los ejemplos de Santander y Logroño que aunque se incluyeron en el régimen preautonómico de Castilla y León luego se constituyeron en Comunidades Autónomas propias, p. 110.

30 Vid. con mayor detalle CALAfEll Ferra, V.J.: «El principio dispositivo negativo: el derecho a no acceder a la autonomía política», en El Futuro Territorial del Estado Español, ob. cit., pp. 227-228.

31 Laguna que a juicio de GARcía Roca constituye no sólo un grave defecto técnico, sino también una clara contradicción con el propio principio de voluntariedad, ob. cit., p. 120.

32 «(1) El territorio federal puede ser reorganizado para garantizar que los Länder, por su tamaño y su capacidad económica, estén en condiciones de cumplir eficazmente las tareas que les incumben. A tal efecto deben tenerse en cuenta las afinidades regionales, los contextos históricos y culturales, la conveniencia económica, así como las exigencias de la ordenación territorial y planificación regional.

(2) Las medidas de reorganización del territorio federal se adoptarán mediante ley federal que requiere la ratificación por referéndum. Deberá darse audiencia a los Länder afectados.

(3) El referéndum se celebrará en los Länder cuyos territorios o partes de territorio pasen a formar parte de un nuevo Land o de un Land conformado con otros límites (Länder afectados). La votación se realizará sobre la cuestión de si los Länder afectados deben subsistir como hasta ahora, o bien ha de formarse el nuevo Land o el Land con nuevos límites. 
do su aprobación por ley federal, que deberá someterse a referéndum. También la constitución italiana ${ }^{33}$ prevé esta posibilidad.

Es cierto que la Constitución no contempla esta posible fusión, salvo el caso de la Disposición Transitoria 4. a . Y en el ámbito autonómico tan sólo algunos Estatutos de Autonomía contemplaron inicialmente esta posibilidad; aunque en las reformas que se operaron una vez se consolidó el proceso autonómico se suprimieron ${ }^{34}$; siendo indicativo de la voluntad de permanencia de cada Comunidad con sus límites territoriales configurados originariamente.

En este sentido, la Disposición adicional primera del Estatuto de Andalucía prevé la ampliación de la Comunidad Autónoma a territorios históricos no integrados en otra Comunidad Autónoma ${ }^{35}$, pero no la fusión entre Comunidades. Y la que si que prevé una segregación de enclaves es la Disposición transitoria tercera del Estatuto de Castilla y León, sujetándola a unas exigencias que requerirían aprobación por Cortes Generales mediante ley Orgánica ${ }^{36}$. Ninguna previsión de

Será positivo el resultado del referéndum sobre la formación de un nuevo Land o de un Land con otros límites, cuando respectivamente la apruebe una mayoría en su futuro territorio y en el conjunto de los territorios o partes de territorio de un Land afectado, cuya pertenencia a un Land haya de ser modificada en igual sentido. Contrariamente, será negativo cuando en el territorio de uno de los Länder afectados una mayoría rechace la modificación; no obstante, el rechazo queda sin efecto si, en una parte del territorio cuya pertenencia al Land afectado debe ser modificada, una mayoría de dos tercios aprueba la modificación, a menos que una mayoría de dos tercios en la totalidad del Land afectado rechace la modificación.

Contemplándose expresamente en las Disposiciones transitorias: Artículo 118 la Reorganización territorial de los Länder del Sudoeste: Baden, Wurtemberg-Baden y Wurtemberg-Hohenzollern que podrá efectuarse, a diferencia de lo establecido en el artículo 29, mediante convenio entre los Länder interesados. Si tal convenio no llegase a concretarse, la reorganización será dispuesta por ley federal que deberá prever una consulta popular. Y el Artículo 118 a) prevé la Reorganización territorial de Berlín y Brandeburgo] que podrá hacerse con participación de sus habitantes con derecho a voto, a través de un convenio entre ambos Länder.

33 Artículo 132: «Se podrá disponer mediante ley constitucional, oídos los Consejos Regionales, la fusión de Regiones existentes o la creación de Regiones nuevas con un mínimo de un millón de habitantes cuando así lo soliciten unos Ayuntamientos que representen como mínimo a un tercio de las poblaciones interesadas y la propuesta se apruebe en referéndum por la mayoría de éstas.

Se podrá, con el voto favorable, expresado en referéndum, de la mayoría de las poblaciones interesadas de la Provincia o Provincias interesadas o del Municipio o Municipios interesados y mediante ley de la República, después de oídos los Consejos Regionales, autorizar que determinadas provincias o municipios que así lo hayan solicitado, queden segregados de una Región e incorporados a otra.

34 El Estatuto de Cantabria aprobado por LO 8/1981, de 30 de diciembre, preveía expresamente en su artículo 58 que la Comunidad pudiera acordar su incorporación a otra limítrofe, a la que le unieran lazos históricos y culturales, estableciendo el procedimiento a tal efecto. Sin embargo, dicha previsión ha desaparece con la reforma del Estatuto por la Ley Orgánica 11/1998.

En los mismos términos aparecía redactado el artículo 44 del Estatuto de la Rioja (LO 3/1982, de 9 de junio). Suprimiéndose dicho precepto en la reforma operada por la LO 2/1999.

35 Que se resolverá por las Cortes Generales, previo acuerdo de las partes interesadas y sin que ello suponga reforma del presente Estatuto, una vez que dichos territorios hayan vuelto a la soberanía española

36 1. Para que un territorio o municipio que constituya un enclave perteneciente a una provincia integrada en la Comunidad Autónoma de Castilla y León pueda segregarse de la misma e incorporarse a otra Comunidad Autónoma será necesario el cumplimiento de los siguientes requisitos: a) Solicitud de segregación, formulada por todos los Ayuntamientos interesados, mediante acuerdo adoptado con el voto favorable de las dos terceras partes del número de hecho y, en todo caso, de la mayoría absoluta de los miembros de cada una de dichas Corporaciones. b) Informes de la provincia a la que pertenezca el territorio, municipio o muni- 
fusión contempla el Estatuto de Autonomía de la Comunidad Valenciana, luego veremos por qué.

Deberíamos plantearnos, pues, si ante la ausencia de previsión constitucional y estatutaria podría plantearse la fusión entre Comunidades Autónomas, que como advierte Sánchez Navarro implica una mayor vinculación que la federación prohibida por el artículo $145.1^{37}$.

Si la delimitación territorial de cada Comunidad parte del principio dispositivo, la fusión habría de plantearse también por la vía de dicho principio, que en palabras de Enric Fossas «permite que sean las Comunidades Autónomas ya constituidas quienes puedan proponer y pactar la modificación de aquellos elementos definidores de su autonomía mediante la reforma de sus respectivos Estatutos de Autonomía ${ }^{38}$. Pues, frente a las posiciones que han mantenido la desnaturalización de dicho principio, convenimos con Aguado Renedo en «la vigencia del principio dispositivo con su (potencial) virtualidad» ${ }^{39}$.

Sin embargo, el proceso de fusión estaría sujeto a las exigencias, primero, de reforma estatutaria, que al no contener previsión alguna al respecto equivaldría a un nuevo proceso estatuyente ya que implicaría la reforma total del Estatuto de Autonomía, debiendo someterse una cuestión de esta índole a referéndum. Y, teniendo que sortear, después, el filtro del procedimiento de reforma estatutaria en las Cortes Generales. Desde nuestro punto de vista, estas exigencias harían inviable, al menos en el marco de la Comunidad Valenciana, la fusión con otras Comunidades Autónomas; sobre todo porque apenas superaría la fase del referéndum.

cipios a segregar y de la Comunidad Autónoma de Castilla y León, favorables a tal segregación, a la vista de las mayores vinculaciones históricas, sociales, culturales y económicas con la Comunidad Autónoma a la que se solicite la incorporación. A tal efecto, la Comunidad Autónoma de Castilla y León podrá realizar encuestas y otras formas de consulta con objeto de llegar a una más motivada resolución. c) Refrendo entre los habitantes del territorio, municipio o municipios que pretendan la segregación, aprobado por mayoría de los votos válidos emitidos. d) Aprobación por las Cortes Generales, mediante Ley Orgánica. 2. En todo caso, el resultado de este proceso quedará pendiente del cumplimiento de los requisitos de agregación exigidos por el Estatuto de la Comunidad Autónoma a la que se pretende la incorporación.

37 Sánchez Navarro, A.: «Artículo 145...», ob. cit., p. 90. De hecho, en un Documento que se filtro de Unión Progreso y Democracia se proponía fusionar algunas Comunidades Autónomas, en concreto Navarra, Aragón y La Rioja, además de las provincias de Burgos y Soria, en una única entidad bajo la denominación de «Ebro Región» con el objetivo de promover el ahorro e incrementar los recursos económicos locales, como la renta de sus ciudadanos. En esta dirección, publicaba sosa Wagner el día 29/08/2013 en El Mundo un artículo en el que sostenía, inspirándose en el modelo alemán, que la futura reforma de la Constitución española no debía contener el nombre de cada Comunidad Autónoma con vistas a poder alterar la envergadura y el número de nuestras autonomías

38 Fossas Espalader, E.: «El principio dispositivo en el Estado Autonómico», Revista de Derecho Políti$c o$, n. $^{\circ} 71-72 / 2008$, p. 153; «...principio dispositivo se manifiesta materialmente en dos elementos esenciales de la estructura territorial en su conjunto: la creación y delimitación de las entidades territoriales, y la distribución del poder entre éstas y las instancias centrales del Estado. Y en varios elementos definitorios de su respectivo autogobierno, contenidos en su norma institucional básica, el Estatuto de Autonomía», cit. p. 163.

39 Aguado Renedo, C.: «El principio dispositivo y su virtualidad actual en relación con la estructura territorial del Estado», Revista de Estudios Políticos, n. ${ }^{\circ}$ 98/1997, p. 158. 
En relación con la absorción no consentida por la Comunidad Autónoma, consideramos que no tendría ningún encaje constitucional. Por tanto, no cabría ni siquiera planteársela.

En síntesis, pese a que dichos pactos, que podrían alterar la actual configuración territorial, no estén vetados constitucionalmente, ni el silencio sobre los mismos pueda entenderse como su prohibición, particularmente en este trabajo apostamos, al menos desde la percepción de la Comunidad Valenciana, por la consolidación del actual mapa territorial, por las razones que se expondrán más adelante.

\section{El proceso estatuyente}

Pese a que el proceso autonómico se circunscribía exclusivamente al territorio propio de la Comunidad Autónoma, sin embargo la fase de elaboración del Estatuto de Autonomía estuvo marcada por fuertes desencuentros entorno a las señas de identidad del pueblo valenciano ${ }^{40}$. El debate encerraba una gran carga ideológica, revelada tanto por los distintos grupos políticos, como por la propia sociedad valenciana, en cuyo seno se vivió un fuerte enfrentamiento social. La firme voluntad de alcanzar el autogobierno estuvo, pues, teñida por dicho conflicto simbólico — denominación, lengua y bandera-; en cuyos detalles no nos adentraremos, por escapar del objeto de este trabajo. Pero lo cierto es que se manifestó con tal virulencia durante la elaboración del Estatuto de Autonomía en las Cortes Generales que estuvo a punto de hacer encallar su aprobación ${ }^{41}$; desbloqueándose mediante un acuerdo que fijaba el nombre de Comunidad Valenciana ${ }^{42}$. Finalmente el Estatuto de Autonomía se aprobó mediante la Ley Orgánica 5/1982, de 1 de julio. Tras esta solución que permitió su aprobación, el Preámbulo intentaba conciliar las posturas antagónicas en los siguientes término: «...Aprobada la constitución española, es, en su marco, donde la tradición valenciana proveniente del Reino de Valencia se encuentra con la concepción moderna del País Valenciano, dando origen a la autonomía valenciana, como integradora de ambas corrientes de opinión que enmarcan lo valenciano en un concepto cultural propio en el estricto marco geográfico que comprende».

40 El proceso se pude estudiar mucho más detalladamente en AlCÁraz Ramos, M.: «Política e ideología en el proceso autonómico», pp. 3 y ss., y GARRIDO MAYOL, V.: «Consideraciones jurídico-políticas del proceso autonómico valenciano», en FerRando BADIA, J. (coord.) Estudios sobre el Estatuto Valenciano, tomo I, Consell Valencià de Cultura, Valencia, 1993, pp. 162 y ss. Más recientemente vid. FliqueTE Lliso, E. «Comentario al Artículo 1» en Comentarios al Estatuto de Autonomía de la Comunitat Valenciana, Garrido Mayol, V. (dr.), Tirant lo Blanch, Valencia 2013, pp. 87 y ss.

41 De hecho tras las modificaciones sobre el nombre en Comisión constitucional, el Pleno rechazo el Proyecto de Estatuto, hasta que en el seno de la Ponencia se alcanzó un acuerdo que desbloqueó el proceso. Sobre la tramitación parlamentaria en Cortes Generales vid. El detallado trabajo de Ripolles SerRANo, R.: «Aspectos técnico-jurídicos del Estatuto de Autonomía de la Comunidad Valenciana», Anuario de Derecho Parlamentario - 12 (2002), 222.

42 BOCD n. $^{\circ} 68$-II, de 2 de febrero de 1982. 
Expresando en su artículo primero que la Comunidad Valenciana es expresión de la voluntad democrática y del derecho de autogobierno del pueblo valenciano, que se constituye en Comunidad, dentro de la indisoluble unidad de la nación española. Con ello se consumaba la voluntad del pueblo valenciano de constituirse en Comunidad Autónoma propia, en el marco del Estado, reflejando con ello su identidad dual, que es precisamente la tesis por la que apostamos en este trabajo, y que es la mayoritariamente sentida por este pueblo.

Esta reafirmación de su singularidad propia ha permitido a la Comunidad Valenciana apostar desde un principio por regular y mantener relaciones de colaboración, tanto con el Estado como con las demás Comunidades Autónomas $^{43}$. Reforzándose dicha voluntad en la reforma de su Estatuto operada en el año $2006^{44}$, en la que se reafirma la relevancia del principio de colaboración como uno de los ejes sobre los que se articula nuestro modelo de organización territorial. Traduciéndose en la incorporación de un Título específico en el que aborda la regulación de determinados instrumentos de colaboración entre la Comunitat y los órganos centrales del Estado, así como con otras Comunidades Autónomas; reforzando con ello el carácter cooperativo de nuestro Estado Autonómico.

De nuevo, en el proceso de reforma del Estatuto se rememoró el constante debate ya referido al plantearse la inclusión de un apartado que contemplaba la celebración de convenios de colaboración con las Comunidades Autónomas de la Antigua Corona de Aragón para mantener los lazos históricos, lingüísticos y culturales $^{45}$. Enmiendas, que, tras ser rechazadas, se volvieron a plantear en el Congreso ${ }^{46}$

43 Conviene recordar que en el marco autonómico, pese al silencio constitucional, Ley Orgánica 5/1982, de 1 de julio, de Estatuto de Autonomía de la Comunidad Valenciana y la Ley 13/1982, de 10 de agosto, de Reintegración y Amejoramiento del Régimen Foral de Navarra fueron los únicos textos estatutarios que regularon expresamente la celebración de Convenios de Colaboración con el Estado.

44 La Ley Orgánica 1/2006, de 10 de abril, de Reforma de la Ley Orgánica 5/1982, de 1 de julio, de Estatuto de Autonomía de la Comunidad Valenciana.

45 Enmienda a la totalidad formulada por el Grupo Parlamentario Esquerra Unida-Els Verds Esquerra Valenciana: Entesa, introducían un apartado 5 en el que se establecía que «La Generalitat Valenciana establecerá convenios de colaboración con las comunidades autónomas de la Antigua Corona de Aragón para mantener los lazos históricos, lingüísticos y culturales». DS. n. ${ }^{\circ} 114$, de 23 de junio de 2005.

46 BOCG n. $^{\circ}$ 196-7, de 16 de noviembre de 2005. En el Congreso algunas enmiendas proponían la previsión expresa de las relaciones especiales de colaboración y la firma de convenios con las Comunidades Autónomas de la antigua Corona de Aragón: en concreto las Enmiendas n.18 firmada por Francisco Rodríguez Sánchez (Grupo Parlamentario Mixto); la n. 62, firmada por el ERC; y la n. 165, firmada por Begoña Lasagabaster Olozábal (GPMX). En otro sentido, la enmienda n. 103 firmada por ERC proponía adicionar nuevos párrafos en los se plasmaba expresamente la obligación de colaboración entre la Generalitat y el Estado, así como con las demás CCAA, estableciendo, asimismo, la participación de la Generalitat en las instituciones, organismos y procedimientos del Estado que afectasen a sus competencias. En la misma dirección, la enmienda n. 106 del mismo grupo, adicionaba un apartado en el que se recogía la participación de la Generalitat en la elaboración de las decisiones estatales que afecten a la ordenación general de la actividad económica. Enmiendas que no se aprobaron por considerar que el párrafo era una reiteración innecesaria, ya que dichas relaciones podían subsumirse en apartados anteriores, DSC n. ${ }^{\circ} 468$, de 8 de febrero de 2006. 
y en el Senado ${ }^{47}$, sin lograr el respaldo de la mayoría en ninguna de las Cámaras.

Esta reciente reforma estatutaria si que incorpora un nuevo precepto (59.4) en el que contempla expresamente en el marco de las relaciones intercomunitarias la especial relación de cooperación que la Generalitat Valenciana mantendrá con las Comunidades Autónomas vecinas que se incluyen el Arco Mediterráneo de la Unión Europea ${ }^{48}$, viniendo, así a reconocerse estatutariamente, la relevancia de dicha cooperación, ya iniciada con anterioridad. Pero, adviértase que se trata de una colaboración que no está circunscrita sólo a la Comunidad limítrofe de Cataluña, sino que se extiende a otras como Andalucía y Murcia, que no aparecen en la Hoja de Ruta de la Independencia de Cataluña.

Todo ello evidencia que la Comunidad Valenciana no ha mostrado reparo en colaborar horizontalmente con otras Comunidades Autónomas, incluida Cataluña; pero siempre y cuando dicha colaboración se planteara por la propia Comunidad, en virtud de su autogobierno, y sin que pudiera poner en cuestión su propia singularidad. En esta irección se instauran los Encuentros entre Comunidades Autónomas para el desarrollo de sus Estatutos de Autonomía, auspiciados desde 2008 por las Comunidades Autónomas que habían reformado sus Estatutos de Autonomía ${ }^{49}$, apareciendo la Comunidad Valenciana como una de las sus impulsoras, remarcando la relevancia de estas relaciones por considerándolas esenciales para avanzar en el desarrollo estatutario desde el consenso y como instrumento esencial para evitar los conflictos territoriales.

\section{LA RESPUESTA INSTITUCIONAL ANTE LA DECLARACIÓN DE DESCONEXIÓN DE ESPAÑA}

Las aspiraciones nacionalistas de formación dels Països Catalans que aparecen reflejadas en la Hoja de Ruta de la Independencia de Cataluña han encontrado, históricamente, respaldo entre distintos grupos de la Comunidad Valenciana:

47 En idéntico sentido, en el Senado, Enmienda n. ${ }^{\circ} 20$ (GPMX), de adición. Artículo 65. Se añade al artículo 59, un punto nuevo, detrás del punto 4, con el siguiente texto: «5. (Nuevo). La Generalitat Valenciana establecerá convenios de colaboración, especialmente con las comunidades autónomas de la antigua corona de Aragón, para mantener los vínculos históricos, lingüísticos y culturales.» BOCG, Senado, n. ${ }^{\circ} 10$, de 2/03/2006. Debate y votación de las Enmiendas DS n. ${ }^{\circ}$ 97, de 1 de julio de 2005.

48 el Acuerdo de cooperación de las Comunidades Autónomas del Arco Mediterráneo Español suscrito el 13-4-94 por los representantes de las CCAA de Andalucía, Cataluña, Murcia, Baleares y Valenciana; BOCG, Senado, Serie I, n. ${ }^{\circ}$ 128, de 25 de mayo de 1994; Congreso de los Diputados, Serie I, n. ${ }^{\circ} 70$, de 13 de junio. En él se acuerda establecer un marco estable de cooperación entre las Administraciones Autonómicas con objeto de promover la articulación territorial en el Arco Mediterráneo Español (AME).

49 Las primeras CCAA que promovieron los encuentros fueron Andalucía, Aragón, Castilla y León, Cataluña, Comunidad Valenciana y las Islas Baleares. 
ciertas entidades culturales, fundaciones, sindicatos, o determinados sectores universitarios han sustentado tradicionalmente estas tesis ${ }^{50}$.

En la arena política las fuerzas que han apoyado las tesis de la unidad política del Països Catalans están situadas en la izquierda nacionalista; por ejemplo, el Bloc contempla en sus Estatutos la posibilidad de unirse a Cataluña alcanzando «la plena soberanía nacional del pueblo valenciano y su plasmación legal mediante una Constitución valenciana que contemple la posibilidad de una asociación política con los países con los que compartimos una misma lengua, cultura e historia» (art. 3). Entre otros partidos que han mantenido estas tesis se encuentran Esquerra Republicana del País Valencià (ERPV) Solidaritat per la Independència (SI), Partit Socialista d'Alliberament Nacional (PSAN), Esquerra Nacionalista Valenciana (ENV), etc. ${ }^{51}$. Y, en los últimos años La Cup está representada en la Comunidad Valenciana por Alternativa per Valéncia-CUP, que tiene como objetivo claro la construcción nacional de los Països Catalans.

El rechazo al nacionalismo independentista ha sido una de las constantes en los distintos procesos electorales de la Comunidad Valenciana, habiéndose revelado como una de las cuestiones que han conducido a la permanencia del Partido Popular durante 20 años en el Gobierno de la Generalitat. De hecho, hasta que las formaciones más nacionalistas no se han alejado, al menos formalmente en sus programas, de las posiciones independentistas no han conseguido alcanzar el po$\mathrm{der}^{52}$. Claro que a ello han contribuido esencialmente los graves problemas de corrupción del Partido Popular en esta Comunidad.

Con este horizonte, no es difícil advertir que la respuesta que los grupos políticos con representación parlamentaria en Les Corts han ofrecido en relación con el proceso de independencia de Cataluña haya sido dispar.

Por un lado, los partidos que conforman actualmente el Gobierno Valenciano han optado por no exteriorizar expresamente su apoyo al proceso independentista catalán. Aunque desde Compromís ${ }^{53}$ se ha producido un respaldo a título personal ${ }^{54}$,

50 Desde la obra de Joan Fuster hasta asociaciones como Acciò Cultural del País Valencià (Eliseu Climent), Escola Valenciana; Editoriales como El Temps o Saò; o asociaciones estudiantiles como Bloc d Estudiants Agermanats (BEA), Sindicat d'Estudiants del Països Catalans son claros exponentes de las mismas. Estas constituyen sólo algunos de los ejemplos; su tratamiento en profundidad escapa del objeto de este trabajo.

51 Adviértase que la Coalición formada por EUPV, ERPV, Els Verds, Alternativa Socialista quedó sin representación parlamentaria en las elecciones autonómicas de mayo de 2015.

52 De hecho, Compromís ha optado en su Programa Electoral por manifestar su alejamiento de los conflictos identitarios, vid. pp. 164-165.

53 Compromís está formada por el Bloc Nacionaliste del País Valencià, Iniciativa del Poble Valencia, y Verds Equo, es una coalición que se creó para concurrir conjuntamente a los comicios electorales de 2011.

Adviertase que la Coalición formada por EUPV, ERPV, Els Verds, Alternativa Socialista quedó sin representación parlamentaria.

54 Entre otros, el europarlamentario del Bloc Jordi Sebastià —integrado en European Free Alianceescribía quejándose de la indiferencia de los valencianos ante el procedimiento catalán. Y Enric Nomdedéu (líder del Bloc) ya respaldó abiertamente el apoyo a la independencia de Cataluña. 
éste no se ha plasmado en un apoyo formal de la Coalición. No obstante, los lazos con formaciones que si que lo hacen siguen existiendo, pues, por ejemplo, en algunos Ayuntamientos se presentó a las elecciones junto con ERC; y, en el marco del Parlamento Europeo, el Bloc (integrado en Compromis) se ha unido a la «European Free Aliance»; grupo conformado por partidos nacionalistas, del que forman parte Esquerra Republicana de Catalunya (ERC) o el Bloque Nacionalista Galego (BNG), que defienden el proceso de independencia catalán. Asimismo, el Consell Nacional del Bloc aprobó el 12 de septiembre de 2015 una resolución en favor del derecho a decidir de Cataluña y en apoyo de los partidos que defendían la independencia respecto a España en la candidatura conjunta de Junts pel sí que se presentó a las elecciones celebradas en Cataluña el 27 de septiembre.

Mientras que la Vicepresidenta del Consell Mónica Oltra ${ }^{55}$, representante de Iniciativa del Poble Valencià, ha manifestado su respaldo al «derecho a decidir». En esta dirección se ha pronunciado expresamente Podemos, que ha apoyado públicamente el derecho a decidir, contemplado en su Programa electoral ${ }^{56}$.

La firmeza del PSOE a nivel estatal, rechazando la independencia y la desconexión de Cataluña, ha contrastado con una mayor tibieza del PSPV, ya que el Presidente de la Generalitat, en principio, se ha mostrado bastante reacio a respaldar declaraciones institucionales rechazando dicha desconexión. Limitándose a manifestar que las declaraciones de Germà Gordó, de Convergència i Unió arrogándose la facultad de expedir la nacionalidad de una hipotética Cataluña independiente, al resto de Países Catalanes, entre los que situó a la Comunidad Valenciana, constituían una falta de respeto ${ }^{57}$. La posición del Presidente valenciano contrasta con la del presidente de Aragón, el socialista Javier Lambán, quien ha pedido poner freno no solo al independentismo catalán sino a sus ansias expansionistas «Es absolutamente indisimulada la pretensión de buena parte del independentismo catalán de anexionarse parte de Aragón, y eso para nosotros es absolutamente insoportable» ${ }^{58}$.

Por otro lado, los partidos con representación parlamentaria que han manifestado una clara posición contraria al proceso independentista han sido el partido Popular y Ciudadanos. Tras la Declaración para iniciar el proceso hacia un «Estado catalán independiente» en forma de República, el PPCV, un día des-

55 Ha manifestado que el derecho a decidir es una propuesta «muy razonable» para aplicar a la hora de resolver el problema territorial en Cataluña; considerando que aplicar el derecho a decidir «no quiere decir» que los catalanes se quieren ir de España. «A lo mejor en Cataluña hay mucha gente que quiere decir que se quiere quedar y quieren decidirlo», remarcando que la situación en Cataluña hay que desbloquearla porque los ciudadanos «no quieren esta paralización». http://www.europapress.es/nacional/noticia-oltra-dice-derecho-decidir-algo-muy-razonable-recuerda-estado-mesa-toda-campana-20151222150417.html

56 Punto 277, pp. 188-189 del Programa Electoral.

57 El País, 24/08/2015, consideradas por el Presidente de la Generalitat como una falta de respeto, y el diputado popular Luis Santamaría. En el mismo sentido pedía el cese de «las injerencias hacia la Comunidad Valenciana».

58 El Periódico de Aragón, EFE 11/11/2015. 
pués, presentó en Les Corts una Declaración Institucional que fijara la posición unánime de la Cámara autonómica en defensa de la unidad de España, que sólo fue mantenida por el grupo proponente y Ciudadanos ${ }^{59}$. Las portavoces de ambos grupos (Eva Ortiz y Carolina Punset) manifestaban que Les Corts no podían permanecer al margen de las intenciones separatistas de una parte de Cataluña, ya que implicaba poner en peligro el pacto constitucional. Aunque dicha Declaración fue rechazada por PSPV, Compromís y Podemos; quienes han venido tachando las propuestas presentadas en este sentido de electoralistas

El rechazo provocó que Isabel Boning (PPCV) anunciara la transformación de dicha Declaración en diversas mociones, con el objeto de remitirlas a sus grupos en los Ayuntamientos de la Comunitat. En concreto, el 30 de octubre el PPCV y Ciudadanos presentaron una Declaración institucional ${ }^{60}$ al Pleno del Ayuntamiento de Valencia, sobre la unidad de España, que también fue rechazada al no alcanzar la unanimidad, ya que no obtuvo el respaldo de los demás grupos políticos ((PSPV, Guanyar y Compromís). Mientras que en el Ayuntamiento de Alicante - con el apoyo de del PPCV y Ciudadanos - prosperó, al abstenerse el tripartito que gobierna dicho Ayuntamiento ${ }^{61}$ (PSPV-PSOE, Guanyar Alacant y Compromís).

$\mathrm{Al}$ igual que se hiciera en otras Cámaras Autonómicas, siendo Castilla y León la primera de ellas ${ }^{62}$, la Síndica del Grupo parlamentario Popular presentó una Proposición no de Ley sobre «La defensa de la unidad de España» ${ }^{63}$, por medio de

59 El Pleno de Les Corts rechazó una iniciativa del PP (a la que se añadió un texto de Ciudadanos) para «poner en valor la cohesión y la unidad de España» y defender el Estado de derecho, los valores constitucionales y «la soberanía nacional, que no es vulnerable ni fraccionable». El portavoz socialista, Manuel Mata, resaltaba que su grupo «no va a jugar al politiqueo»; mientras que la diputada de Compromís Mireia Mollà acusó al PP de «banalizar el debate», y el representante de Podemos, Antonio Estañ, entendió que presentar esta declaración cuando se sabía que no habría era «frívolo». Podemos manifiestó su rechazo al entender que se da en la declaración una visión de España que entienden poco «abierta y plural». considerando que constituye una «usurpación de competencias» de otra Comunidad autónoma, y aduciendo que, además, éste «no es el principal problema de los españoles».

La posición de Carolina Punset mostrándose «indignada» al no haberse alcanzado «un consenso de mínimos» ante «la mayor agresión que ha sufrido la convivencia pacífica y de progreso en los últimos 30 o 40 años». Vid. Declaraciones de los representantes de los distintos grupos políticos en el Archivo de Audio de Les Corts, recogidas, asimismo, por los diversos medios de comunicación.

60 En la que mantienen que España «es hoy una gran nación integrada por un conjunto de bombres y mujeres iguales en derechos y obligaciones. Un país donde se respeta la pluralidad, la singularidad y la diversidad de los distintos territorios que la forman siendo éste el fundamento de su indisoluble unidad».

61 Los 15 concejales que sostienen el actual equipo de gobierno, seis del PSOE, seis de Guanyar Alacant y tres de Compromis, se han abstuvieron al considerarla una «pantomima».

62 Tanto la Diputación como el Ayuntamiento de León manifestaronsu adhesión a la Declaración Institucional impulsada las Cortes en defensa de la unidad de España.

63 BOCV 31, de 6-11-2015. En la que se exponía que la iniciativa presentada por los grupos parlamentarios catalanes CUP y Junts pel Sí es «contraria a la Constitución española, a las leyes, al sentir mayoritario de los catalanes y a la soberanía del pueblo español; pero, sobre todo, contraria al ejemplo de convivencia, paz y concordia en la que han vivido los españoles en estos últimos treinta y siete años, resultado del espíritu integrador de los valores e ideologías de todos los ciudadanos y de los grupos en los que se integran, así como también de nuestra pluralidad y diversidad territorial que caracteriza nuestra carta magna de 1978»... 
la cual reclamaba, nuevamente, el reconocimiento del valor de la Constitución, y proponía que Les Corts manifestaran su opinión «unánime en defensa de la unidad de España, de la soberanía nacional», reclamando su posición en contra de la declaración de independencia ${ }^{64}$.

Si bien, dicha proposición fue retirada ${ }^{65}$ al alcanzarse un acuerdo entre el PSPV y el PPCV con el objeto de no interferir en el pacto que pudieran alcanzar los líderes nacionales de ambos partidos, frente al proceso independentista; ya que ambos se habían reunido en Moncloa para trabajar coordinadamente en defensa de la Constitución ante la Declaración soberanista, expresando su rechazo hacia la misma.

Por su parte Ciudadanos ${ }^{66}$ presentó una Proposición No de Ley «Sobre el cumplimiento y respeto del sistema constitucional». Partiendo de que la Declaración de Independencia instaba a iniciar solemnemente el proceso de creación del «Estado catalán» y a poner en marcha la tramitación de determinadas leyes; requiriendo adoptar las medidas pertinentes para abrir un proceso de «desconexión del Estado español, deslegitimando cualquier decisión del Tribunal Constitucional. Los proponentes de la Proposición no de Ley sostenían que: «...la Constitución y el resto del ordenamiento vigente son la garantía de la igualdad de derechos de todos los españoles en cualquier parte de España, que son además el marco de convivencia del que libremente todos los ciudadanos españoles nos hemos dotado y, que por tanto, ninguna institución democrática española puede permanecer ajena a un reto contra la legalidad democrática de esta magnitud.

Proponiendo, por ello, una Resolución ${ }^{67}$ que instara al Consell y a todos los ayuntamientos, diputaciones y demás entes públicos a efectuar una declaración que impidiera la desobediencia a las leyes democráticamente aprobadas, ni de los Tribunales, «reafirmando la vigencia de todos los principios constitucionales, y expresando su máximo compromiso con la construcción del proyecto común que

64 3. Les Corts quieren dejar constancia que ninguna institución o representante político puede atribuirse la capacidad de incumplir las leyes democráticas. 4. Asimismo, Les Corts desean destacar y poner en valor la fortaleza de nuestras instituciones y la indivisibilidad de la soberanía nacional, que consideramos que no puede ser ni vulnerable ni fraccionable. 5. Les Corts instan al Consell para que éste, a su vez, inste a todos los poderes públicos, administraciones públicas y sociedad civil a defender nuestra Constitución española, norma institucional básica que desde sus valores y principios permite afrontar nuestros problemas y anhelos dentro del respeto a las reglas de juego adoptadas libre y democráticamente, evitando planteamientos que puedan poner en peligro la estabilidad y la seguridad de todos.

65 En el Pleno de Les Corts, en la sesión del 11 de noviembre de 2015, BOCV 34, de 18-11- 2015.

66 Proposición no de Ley de Ley de tramitación especial de urgencia, n. ${ }^{\circ} 002045$.

67 1. Oponiéndose a que ningún parlamento, gobierno o institución política pueda efectuar ninguna declaración por la que se reconozca que ningún parlamento, gobierno o institución política pueda desobedecer las leyes democráticamente aprobadas, ni las resoluciones de los tribunales, ni situarse por encima de la soberanía popular, que corresponde, de acuerdo con la Constitución, al conjunto del pueblo español. 2. Reafirmando la plena vigencia de todos los principios democráticos que emanan de la Constitución, en particular la igualdad de todos los españoles ante la ley, con independencia del territorio donde residan. 3. Solidarizándose con todos los ciudadanos de Cataluña ante el reto a las libertades, a la igualdady a la democracia que supone la intención de algunas fuerzas políticas de incumplir la Constitución, las leyes y las resoluciones de los tribunales. 4. Expresando su máximo compromiso con la construcción del proyecto común que es España, de la mano de nuestros conciudadanos catalanes y junto con todos los españoles, en el marco de la Unión Europea. 
es España, de la mano de nuestros conciudadanos catalanes y junto con todos los españoles, en el marco de la Unión Europea».

A la Proposición no de Ley presentada por Ciudadanos se formularon dos Enmiendas de cariz contrapuesto: una del PPCV que se tradujo en la incorporación del apartado tercero de la Resolución definitivamente aprobada. Mientras que la enmienda conjunta planteada por PSPV, Compromís y Podemos-Podem solicitaba sustituir íntegramente el texto de la Proposición no de Ley Inicial. En ella se ponía de manifiesto la distinta visión en materia de organización territorial, ya que en la Exposición de Motivos expresaban la diversidad y la reivindicación de un Estado plural, considerándolos plenamente coherentes con la configuración histórica de España. Por ello, manifestando su respeto a la legalidad y lealtad a la Constitución Española, consideraban que era necesario un nuevo pacto territorial dentro de un amplio cambio constitucional ${ }^{68}$.

Como podrá apreciarse, esta propuesta va más allá del contenido formulado en la Proposición no de Ley debatida, ya que propone un cambio constitucional para generar un nuevo marco de convivencia en el que, entre otras medidas más amplias, se clarifiquen competencias, reclamando un nuevo sistema de financiación autonómico, la dotación de mecanismos de cooperación institucional, y el reconocimiento de los hechos diferenciales junto con la delimitación del mapa territorial. Incluso la modificación del control de la constitucionalidad de los estatutos de autonomía par evitar que se repita la anulación parcial de un texto aprobado, previamente, por la ciudadanía. Que supone, en definitiva, un respaldo al proceso catalán de reforma de su Estatuto de Autonomía.

Finalmente, la PNL presentada por Ciudadanos, a la que se incorporaba la Enmienda planteada por el PPCV se aprobó con el voto favorable de los diputa-

68 Propuesta de Resolución: 1. Las Cortes Valencianas reconocen el necesario respeto al Estado de Derecho en democracia. 2. Las Cortes Valencianas manifiestan el papel indispensable que tienen las autonomías en la vertebración del Estado y la cohesión social. 3. Las Cortes Valencianas instan al Conselll de la Generalitat para que se dirija al gobierno de España instándole a la convocatoria de la Conferencia de Presidentes Autonómicos para analizar la situación. 4. Las Cortes Valencianas insten al Consell de la Generalitat para que se dirija al gobierno del Estado, a todos los poderes públicos, administraciones y sociedad civil para generar un nuevo marco de convivencia entre sus territorios y ciudadanos a través de un proceso de cambio constitucional que incluya: a) el reconocimiento expreso del mapa territorial español con la incorporación a la Constitución de los hechos diferenciales, de las singularidades políticas, institucionales, territoriales, culturales y lingüísticas, expresión de nuestra diversidad. b) la clarificación y la delimitación de las competencias, las responsabilidades y las obligaciones para acabar con los conflictos actuales. c) el acuerdo constitucional de un nuevo sistema de financiación autonómico justo y equitativo, que otorgue certeza, estabilidad y equilibrio al sistema de reparto de los recursos públicos y que garantice la suficiencia y la autonomía política. d) el reconocimiento como derechos fundamentales de todas las personas que residan en España, de los servicios sociales básicos, la sanidad, la educación y las pensiones. e) la dotación de mecanismos de cooperación institucional, modificando el control de la constitucionalidad de los estatutos de autonomía par evitar que se repita la anulación parcial de un texto aprobado, previamente, por la ciudadanía. 5. Las Cortes Valencianas manifiestan su voluntad de articular una respuesta política capaz de integrar desde la voluntad democrática todas las sensibilidades y las identidades, así como su deseo expreso de contar con Cataluña para dicho proyecto común, del cual es parte imprescindible. 
dos de Ciudadanos, del Grupo Parlamentario Popular, absteniéndose el PSPV; mientras que los diputados de Compromís y Podemos-Podem votaron en contra.

En definitiva, esta respuesta institucional evidencia por un lado, el condicionamiento del PSPV ${ }^{69}$ respecto de sus socios de Gobierno, evitando que se manifieste con la misma rotundidad con que lo ha hecho el Partido Socialista en otros ámbitos al rechazar la Declaración de Independencia de Cataluña; aunque disintiendo de otros grupos políticos entorno a las soluciones al conflicto catalán. Por otro lado, institucionalmente, las posiciones mantenidas en las Cortes Valencianas revelan puntos de vista disímiles en orden a la organización territorial y, en concreto, a la resolución del problema catalán. Pero, pude advertirse que en ninguna de las proposiciones ni en sus enmiendas se plantea la asunción de las tesis mantenidas en la Hoja de Ruta del Independentismo Catalán referidas a la incorporación de la Comunidad Valenciana al Estado Catalán Independiente.

\section{LA IDENTIDAD DUAL DE LA COMUNIDAD VALENCIANA EN EL MODELO DE ORGANIZACIÓN TERRITORIAL}

Como acabamos de ver, las pretensiones de independencia de Cataluña y su desmembración del Estado no han conseguido el aval de las instituciones valencianas; de modo que, aun con matices importantes, las fuerzas políticas con representación parlamentaria han manifestado bien el rechazo rotundo a dicha independencia tal y como se ha planteado; bien el deseo de reconocer a Cataluña como parte imprescindible del proyecto común, integrando las sensibilidades e identidades. Además, tampoco se han considerado ni siquiera institucionalmente las pretensiones mantenidas en la Hoja de Ruta del Independentismo referidas a la Comunidad Valenciana.

Ello evidencia que la Comunidad Autónoma Valenciana ha mantenido constantemente una clara identidad dual, ya que, ni política ni sociológicamente, ha manifestado ningún conflicto entre su autonomismo — con su identidad propia-y su pertenencia al Estado.

En efecto, como tendremos ocasión de ver a continuación, desde la entrada en vigor de la Constitución y el subsiguiente arranque del proceso de descentralización territorial, la posición defendida fue siempre la de constituirse en Comunidad Autónoma propia, reivindicando su propia identidad, así como su pleno acomodo a la pertenencia a un Estado como el diseñado por el texto constitucional español, que le permitiera conciliar su propia capacidad de autogobierno en el marco estatal.

69 Así desde el PSPV, Manuel Mata España ha manifestado que España se enfrenta a «uno de los mayores problemas políticos de su historia reciente, al menos desde la Constitución de 1978», resaltando que «es inviable cualquier solución independentista». 
Los datos que nos ofrece el Cis vienen a confirmar esta clara identidad dual de los valencianos. Así ante la pregunta formulada en la Comunidad Valenciana que plantea ¿Con cuál de las siguientes frases se identifica Ud. en mayor medida? La respuesta confirma dicha identidad dual ya que la gran mayoría se sienten al mismo tiempo tanto españoles como valencianos: Se siente únicamente español/a $(21,1)$, Se siente más español/a que valenciano/a $(9,4)$, Se siente tan español/a como valenciano/a $(57,7)$, Se siente más valenciano/a que español/a $(5,7)$, Se siente únicamente valenciano/a $(1,7)$, N.S. $(1,2)$, N.C. $(3,1)$, (N) (989) - Estudio n. ${ }^{\circ}$ 3088, de mayo/junio de 2015 del Banco de Datos el Centro de Investigaciones Sociológicas (CIS), pregunta.$^{\circ} 28^{70}$.

Dicha tendencia se confirma ante la pregunta entorno a algunas fórmulas alternativas de organización territorial del Estado en España, recibiendo un mayor respaldo la fórmula relativa a un Estado como el actual, frente a la posibilidad de convertirse la Comunidad Valenciana en un Estado independiente, que recibe un respaldo muy escaso ${ }^{71}$. Un Estado con un único Gobierno central sin autonomías $(24,3)$, Un Estado en el que las comunidades autónomas tengan menor autonomía que en la actualidad (16,0), Un Estado con Comunidades Autónomas como en la actualidad (36,9), Un Estado en el que las comunidades autónomas tengan mayor autonomía que en la actualidad (10,3), Un Estado en el que se reconociese a las comunidades autónomas la posibilidad de convertirse en estados independientes $(3,4)$, N.S. $8,1(8,1)$, N.C. $1,0(1,0),\left(\right.$ (N) (989) -Ídem. Pregunta n. ${ }^{\circ} 29-$.

En definitiva, dicha identidad dual valenciana, manifestada, tanto institucionalmente como socialmente, es la reflejada en la propia norma institucional básica de la Comunidad Valenciana, cuya reforma operada por la Ley Orgánica 1/2006, de 10 de abril, remarca los principios de lealtad institucional y solidaridad como pilares básicos del Estado Autonómico. Y desde esta posición difícilmente podría respaldarse un proceso de independencia que no siguiera los cauces constitucionales.

TITLE: The process of independence of Catalonia: your view from the Comunitat Valenciana

ABSTRACT: This paper examines the Catalan movement towards independence from the perspective of the Valencian Community and analyses the institutional response to the Declaration of the Catalan parliament that initiated the "process of disconnection from Spain". It also studies the impact that this process has

70 Estudio Postelectoral elecciones autonómicas y municipales de 2015. Comunidad Valenciana.

71 De hecho la confirmación de que los valencianos no son nacionalistas se ha mantenido como una constante, como revela Xavier Coller, en su trabajo «Los políticos valencianos en el contexto español», Revista Valenciana d'Estudis Autonómics 41/41, especialmente pp. 124 y ss. Así lo han mantenido MANUEL García Ferrando y Antonio Ariño Villarroya en Los nuevos valores de los valencianos, Tirant lo Blanch, Valencia, 1999.

UNED. Teoría y Realidad Constitucional, núm. 37, 2016, pp. 381-404 
had on a Community in which there has not been a political or social conflict generated by the coexistence of baving both an autonomous identity and forming part of the Spanish nation.

Resumen: Este trabajo aborda el proceso independentista de Cataluña desde la perspectiva de la Comunidad Valenciana: analizando, por un lado, la respuesta que se ha ofrecido institucionalmente a la Declaración del Parlamento de Cataluña que inicia el «proceso de desconexión de España». Por otro, estudia la incidencia de dicho proceso en el marco de una Comunidad dual, que no ha manifestado ni política ni sociológicamente ningún conflicto entre su autonomismo — con su identidad propia - y su pertenencia al Estado.

KeY words: Catalan Independence, Community of Valencia, Territorial organization.

Palabras clave: Independencia de Cataluña; Comunidad Autónoma Valenciana, Organización territorial.

FECHA DE RECEPCIÓN: 09.12.2015

FECHA DE ACEPTACIÓN: 15.01.2016 